Proc. Indian Acad. Sci. (Earth Planet. Sci.), Vol. 91, No. 1, March 1982, pp. 43-54.

(c) Printed in India.

\title{
Spectral interpretation of gravity anomalies due to horizontal slab like bodies with lateral variation of density
}

\author{
N L MOHAN and S V SESHAGIRI RAO \\ Centre of Exploration Geophysics, Osmania University, Hyderabad 500 007, India \\ MS received 10 June 1982; revised 23 November 1981

\begin{abstract}
Fourier spectrum of the gravity effect due to a horizontal slab with lateral variation of density is derived. By analysing this spectrum a procedure is formulated to determine the parameters of the causative body viz. depths to the upper and lower surfaces, width of the horizontal portion having the lateral density variation and the lateral density gradient. Two synthetic models and a field example are discussed to establish the validity of the procedure formulated. This is much simpler than Gendzwill's type curves method.
\end{abstract}

Keywords. Fourier spectrum; latéral variation of density; gravity anomalies; horizontal slab.

\section{Introduction}

The gradual horizontal change in density between two rock types, rather than a discrete density change across a single boundary is a common phenomenon. It can be found in areas where there are two rock types separated by interbedding, intrusive plutons characterised by lit-par-lit structure at their contacts, change in density through a steeply dipping sequence of beds, extensive contact metamorphism, change in regional metamorphism or wide complicated fault zones.

One such rock type is the horizontal slab in which there is a linear change of density between two adjacent slabs of constant density. Apparently the gravity effect due to the gradational density contrast resembles that of the step model, but actually it differs from it to a large extent. Gendzwill (1970) presented a series of type curves and interpretation nomograms which show the characteristics of the gradational model. Subsequently Garde (1974) applied this analysis for oceanic ridges.

In the present paper we analyse the gravity effect of a horizontal slab with lateral density variation by considering its Fourier transformation. The procedures formulated can determine the parameters of the causative body namely depths to the upper and lower surfaces, width of the horizontal trace and lateral density variation. The method is tested on two synthetic examples and a field example.

\section{Gravity effect due to a horizontal slab with lateral density pariation}

The vertical gravity effect due to a horizontal slab situated in the $X-Z$ plane (figure 1a) and its density varying along the $X$-direction is given by (Novosolitskii 1965) 


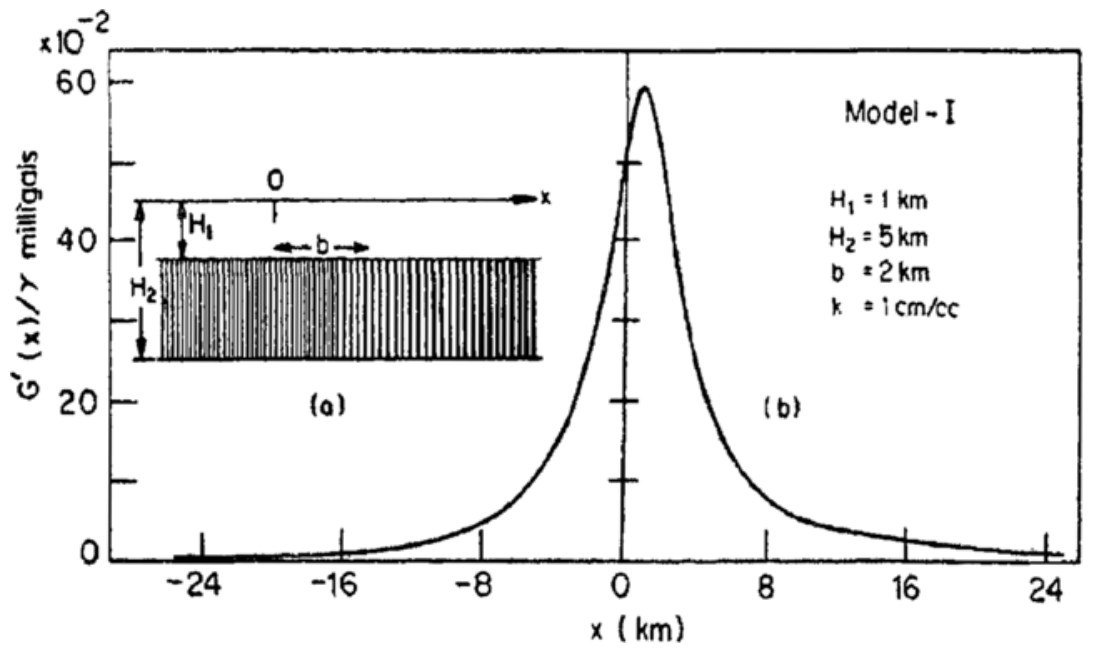

Figure 1 a. Horizontal slab model with gradational density contrast, b. Computed horizontal derivative of the gravity effect of the horizontal slab model with gradational density contrast.

$$
G(x)=\gamma \int_{-\infty}^{\infty} \rho\left(x^{\prime}\right) \ln \frac{H_{2}^{2}+\left(x-x^{\prime}\right)^{2}}{H_{1}^{2}+\left(x-x^{\prime}\right)^{2}} \mathrm{~d} x^{\prime}
$$

where

$x$ is a fixed point of $x^{\prime}, \rho\left(x^{\prime}\right)$ the density, $H_{1}$ and $H_{2}$ depths of the upper and lower faces of the slab respectively and $\gamma$ is the universal gravitational constant.

Following Gendzwill (1970), we assume

$$
\begin{aligned}
& \rho\left(x^{\prime}\right)=0, \quad-\infty<x^{\prime}<0, \\
& \rho\left(x^{\prime}\right)=k x^{\prime}, \quad 0<x^{\prime}<b, \\
& \rho\left(x^{\prime}\right)=k b, \quad b<x^{\prime}<\infty,
\end{aligned}
$$

where $k$ is the linear density gradient and $b$ is the width of the zone of density change. Integrating the RHS of (1) using (2) we get,

$$
\begin{aligned}
G(x) & =\gamma k\left[\pi b\left(H_{2}-H_{1}\right)+\frac{H_{2}^{2}-(x-b)^{2}}{2} \ln \left(H_{2}^{2}+(x-b)^{2}\right)\right. \\
& -2 H_{2}(x-b) \tan ^{-1}\left((x-b) / H_{2}\right)-\frac{H_{1}^{2}-(x-b)^{2}}{2} \ln \left(H_{1}^{2}+(x-b)^{2}\right) \\
& +2 H_{1}(x-b) \tan ^{-1}\left((x-b) / H_{1}\right)-\frac{H_{2}^{2}-x^{2}}{2} \ln \left(H_{2}^{2}+x^{2}\right) \\
& \left.+2 H_{2} x \tan ^{-1}\left(x / H_{2}\right)+\frac{H_{1}^{2}-x^{2}}{2} \ln \left(H_{1}^{2}+x^{2}\right)-2 H_{1} x \tan ^{-1}\left(x / H_{1}\right)\right] .(3)
\end{aligned}
$$


Differentiating (3) w.r.t. $x$ we get the horizontal derivative of the gravity effect

$$
\begin{aligned}
G^{\prime}(x) & =\gamma k\left[x \ln \frac{H_{2}^{2}+x^{2}}{H_{1}^{2}+x^{2}}-2 H_{1} \tan ^{-1}\left(x / H_{1}\right)+2 H_{2} \tan ^{-1}\left(x / H_{2}\right)\right. \\
& -(x-b) \ln \frac{H_{2}^{4}+(x-b)^{2}}{H_{1}^{2}+(x-b)^{2}}+2 H_{1} \tan ^{-1}\left((x-b) / H_{1}\right) \\
& -2 H_{2} \tan ^{-1}\left((x-b)\left(H_{2}\right)\right] .
\end{aligned}
$$

\section{Fourier transform of the gravity effect}

The Fourier transform of $G^{\prime}(x)$ is given by

$$
\tilde{G}(\omega)=\int_{-\infty}^{\infty} G^{\prime}(x) \exp (-i \omega x) \mathrm{d} x
$$

where $\omega$ is the angular spatial frequency.

Substituting (4) in (5) and evaluating the integral we get the real and imaginary components of the Fourier spectrum $G^{\prime}(x)$ as

$$
\operatorname{Re} \tilde{G}(\omega)=\frac{2 \pi \gamma K}{\omega^{2}}\left(\exp \left(-\omega H_{1}\right)-\exp \left(-\omega H_{2}\right)\right) \sin \omega b
$$

and

$$
\operatorname{Im} \tilde{G}(\omega)=\frac{2 \pi \gamma K}{\omega^{2}}\left(\exp \left(-\omega H_{1}\right)-\exp \left(-\omega H_{2}\right)\right)(1-\cos \omega b)
$$

The amplitude spectrum is given by

$$
\begin{aligned}
\tilde{A}(\omega) & =\left(\{\operatorname{Re} \tilde{G}(\omega)\}^{2}+\{\operatorname{Im} \tilde{G}(\omega)\}^{2}\right)^{1 / 2} \\
& =\frac{2 \pi \gamma K}{\omega^{2}}(2-2 \cos \omega b)^{1 / 2}\left(\exp \left(-\omega H_{1}\right)-\exp \left(-\omega H_{2}\right)\right) .
\end{aligned}
$$

\section{Analysis of the Fonrier spectrum}

It is evident from (6), (7) and (8) that the components of the Fourier spectrum mainly depend on $\exp \left(-\omega H_{1}\right)$ and $\exp \left(-\omega H_{2}\right)$. Assuming $H_{2} \gg H_{1}$, we may reasonably conclude that, at higher frequencies (Rao and Avasthi 1973; Bhimasankaram et al $1977,1978)$ the contribution of the terms containing $\exp \left(-\omega \mathrm{H}_{2}\right)$ is negligible. 
Hence we write

$$
\begin{aligned}
& \operatorname{Re} \tilde{G}(\omega)=\frac{2 \pi \gamma K}{\omega^{2}} \sin \omega b \exp \left(-\omega H_{1}\right) \\
& \operatorname{Im} \tilde{G}(\omega)=\frac{2 \pi \gamma K}{\omega^{2}}(1-\cos \omega b) \exp \left(-\omega H_{1}\right)
\end{aligned}
$$

and

$$
\tilde{A}(\omega)=\frac{2 \pi y K}{\omega^{2}}(2-2 \cos \omega b)^{1 / 2} \exp \left(-\omega H_{1}\right)
$$

From (8), it is clear that $\operatorname{Re} \tilde{G}(\omega)$ vanishes, if

$$
\begin{aligned}
\omega_{1} b & =\pi, \\
\text { or } \quad \omega_{2} b & =2 \pi, \\
\ldots & =\ldots \\
\ldots & =\ldots \\
\ldots & =\ldots \\
\text { or } \quad \omega_{n} b & =n \pi .
\end{aligned}
$$

The parameter $b$ can be evaluated from eq. (12) as

$$
b=\frac{\pi}{\omega_{1}}
$$

or in a more general way

$$
b=\frac{1}{N} \sum_{n=1}^{N} \frac{n \pi}{\omega_{n}}
$$

Equation (11) can be rewritten as

$$
\frac{\omega^{2} \tilde{A}(\omega)}{(2-2 \cos \omega b)^{1 / 2}}=2 \pi \gamma K \exp \left(-\omega H_{1}\right)
$$

or

$$
\ln \left[\frac{\omega^{2} \tilde{A}(\omega)}{(2-2 \cos \omega b)^{1 / 2}}\right]=\ln [2 \pi \gamma K]-\omega H_{1}
$$

Thus $H_{1}$ is evaluated from the slope of the curve $\ln \left[\frac{\omega^{2} \tilde{A}(\omega)}{(2-2 \cos \omega b)^{1 / 2}}\right]$ vs. $\omega$. 
The intercept obtained by extrapolating the linear curve gives $2 \pi \gamma K$ from which $K$ can be determined.

Finally $H_{2}$ can be evaluated from (8) as

$$
H_{2}=\frac{\bar{A}(0)}{2 \pi \gamma K b}+H_{1}
$$

\section{Application}

In order to test the applicability of the method outlined above for evaluating the parameters of the causative body, we consider two synthetic models (see table 1).

Since the field data will always be in discrete form, the computed data of the gravity effects with the parametric values given in table 1 (figures $1 \mathrm{~b}$ and 5) is accordingly modified by the digitization at an interval of $0.1 \mathrm{~km}$.

The Discrete Fourier Transform of the horizontal gradient of the gravity effect $G^{\prime}(x)$ is given by (Cochran et al 1967).

$$
\tilde{G}\left(n \omega_{0}\right)=\sum_{l=0}^{N=1} G^{\prime}(l \cdot \Delta x) \exp \left(-i n \omega_{0} / \Delta x\right),
$$

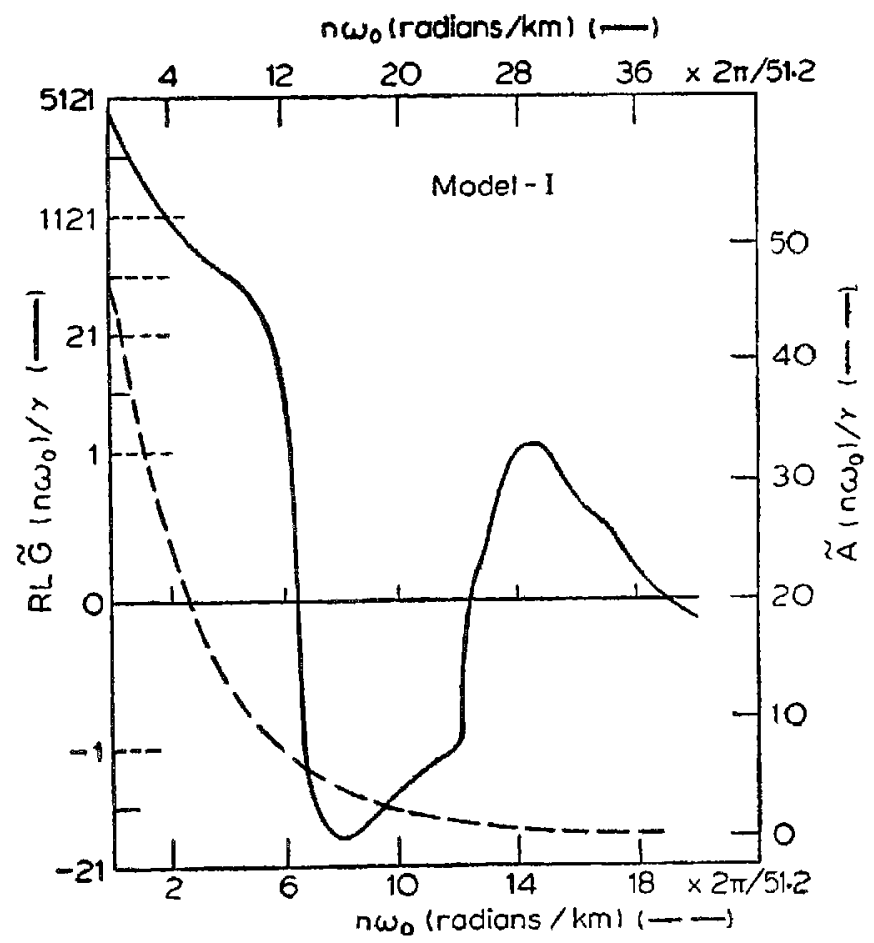

Figure 2. Graphs of $\tilde{G}\left(n \omega_{0}\right) / \gamma$ and $\tilde{A}(n \omega)_{0} / \gamma$ us. $n \omega_{0}$ of the gravity effect. 
Table 1. Theoretical examples

\begin{tabular}{lcccc}
\hline Parameters & $\begin{array}{c}\mathrm{b} \\
(\mathrm{km} .)\end{array}$ & $\begin{array}{c}\mathrm{H}_{1} \\
(\mathrm{~km} .)\end{array}$ & $\begin{array}{c}\mathrm{H}_{2} \\
(\mathrm{~km} .)\end{array}$ & $\begin{array}{c}\mathrm{K} \\
(\mathrm{gm} / \mathrm{c} . \mathrm{c})\end{array}$ \\
\hline Assumed & 2 & 1 & 5 & 1 \\
Evaluated & 2.04 & 0.98 & 4.44 & 1.05 \\
Assumed & 3 & 3 & 12 & 0.3 \\
Evaluated & 3.12 & 3.23 & 10.03 & 0.31 \\
\hline
\end{tabular}

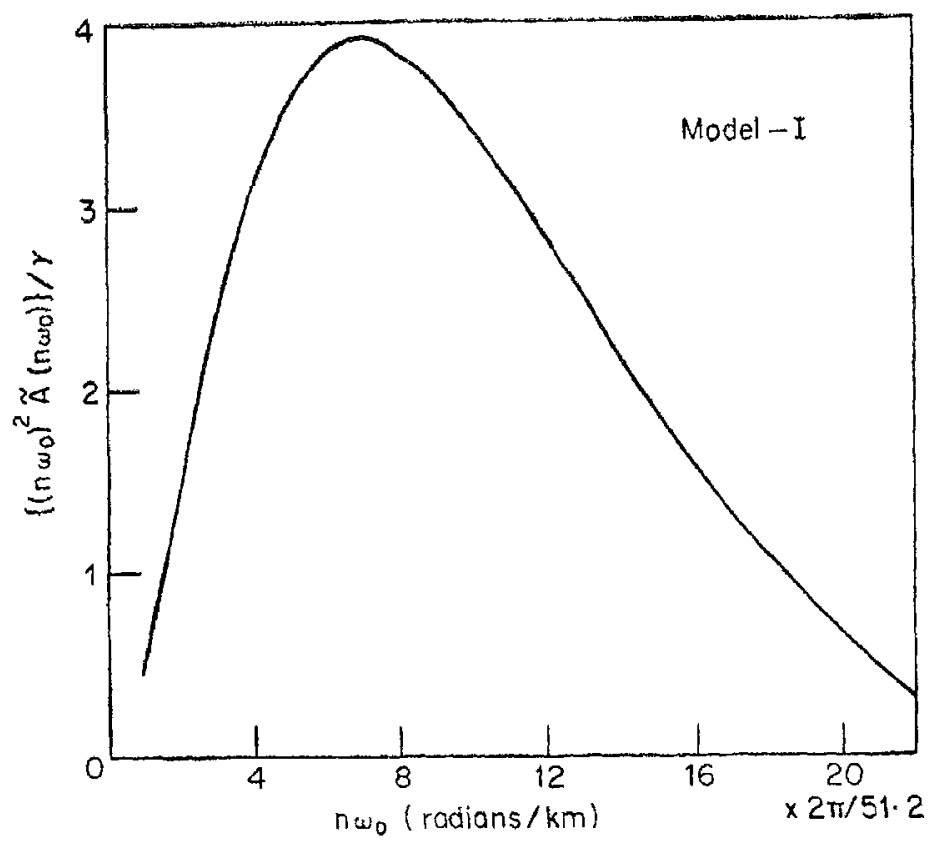

Figure 3. Graph of modified amplitude spectrum $\left(n \omega_{0}\right)^{8} A\left(n \omega_{0}\right) / \gamma$ vs. $n \omega_{0}$.

where $\omega_{0}$ is the fundamental frequency $(2 \pi / N \cdot \Delta x), \Delta x$ is the sample interval and $N$ the number of samples. In the present case $\Delta x=0.1 \mathrm{~km}, N=512$ and $\omega_{0}=2 \pi /(512 \times 0.1) \mathrm{radians} / \mathrm{km}$. The curves $\operatorname{Re} \tilde{G}\left(n \omega_{0}\right) / \gamma, \tilde{A}\left(n \omega_{0}\right) / \gamma$ and $\ln \left[\frac{\left(n \omega_{0}\right)^{2} \tilde{A}\left(n \omega_{0}\right)}{\gamma\left(2-2 \cos n \omega_{0} b\right)^{1 / 2}}\right]$ versus $n \omega_{0}$ of model $I$ are shown in figures 2,3 and 4 and of model II in figures 6,7 and 8 . It may be mentioned here that the ratio between $H_{1}$ and $H_{2}$ for the model II $(1: 4)$ is less when compared to the ratio for the model I $(1: 5)$. As the ratio decreases the erratic oscillations of the Fourier components $\operatorname{Re} \tilde{G}\left(n \omega_{0}\right) / \gamma$ and $\tilde{A}\left(n \omega_{0}\right) / \gamma$ vs $n \omega_{0}$ increase. This is clear from figures 2 and 6 . The irregular oscillations are not shown particularly in figure 6 at higher frequencies. A detailed study has already been made (Mohan et al 1980) and further explanation may not be necessary here. Using these graphs and equations (14), (16) and (17) the parameters are evaluated and shown below. 


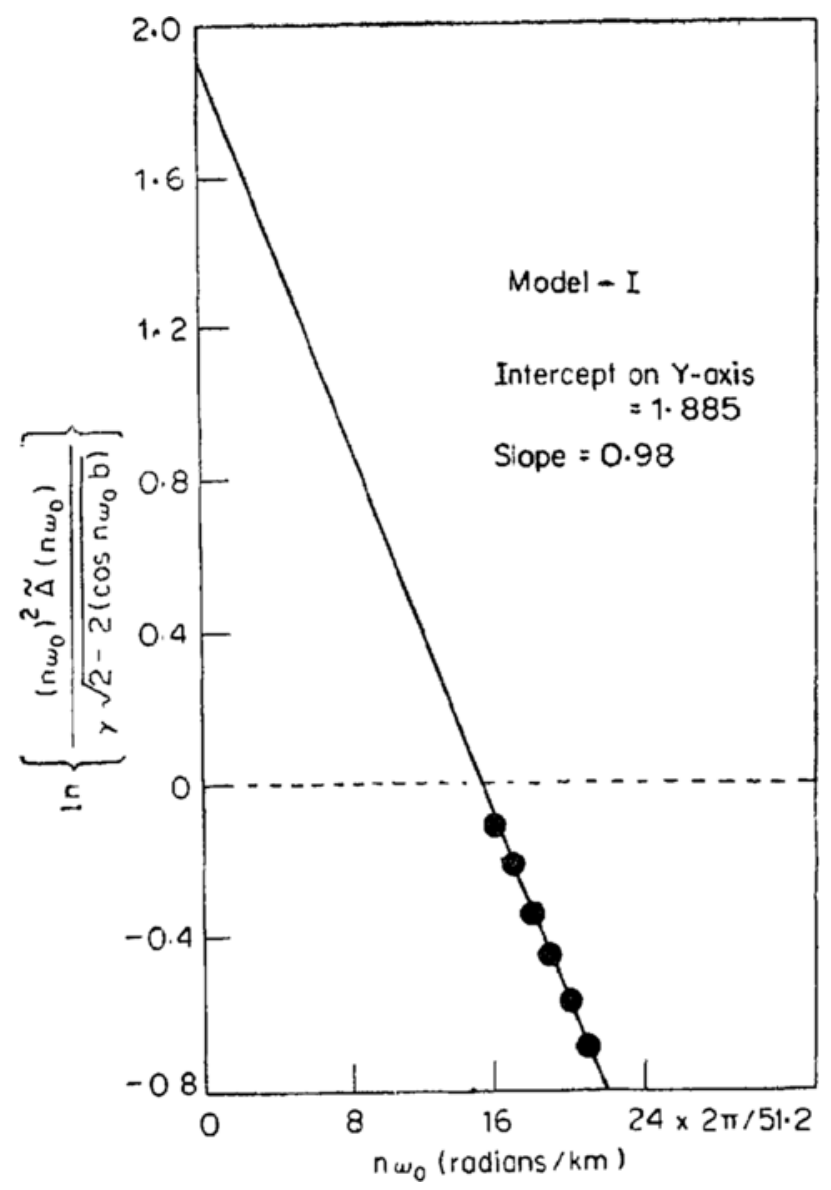

Figure 4. Graph of $\ln \left[\frac{\left(n \omega_{0}\right)^{2} \tilde{A}\left(n \omega_{0}\right)}{\gamma\left(2-2 \cos n \omega_{0} b\right)^{1 / 2}}\right]$ vs. $n \omega_{0}$.

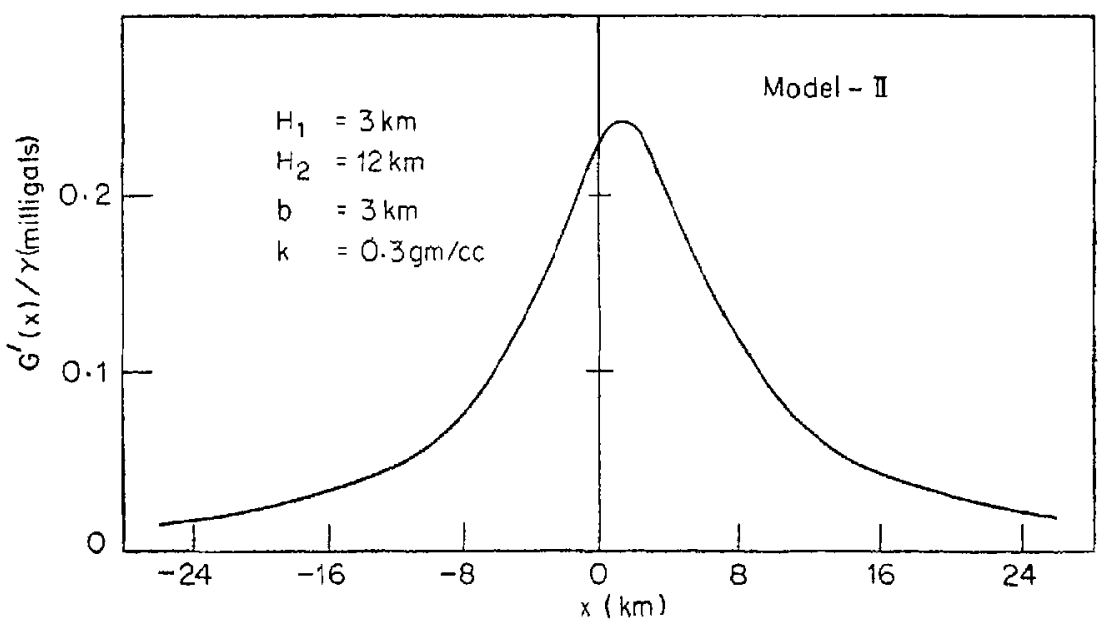

Figure 5. Computed horizontal derivative of the gravity effect of the horizontal slab model with gradational density contrast.

E. P. S. -4 


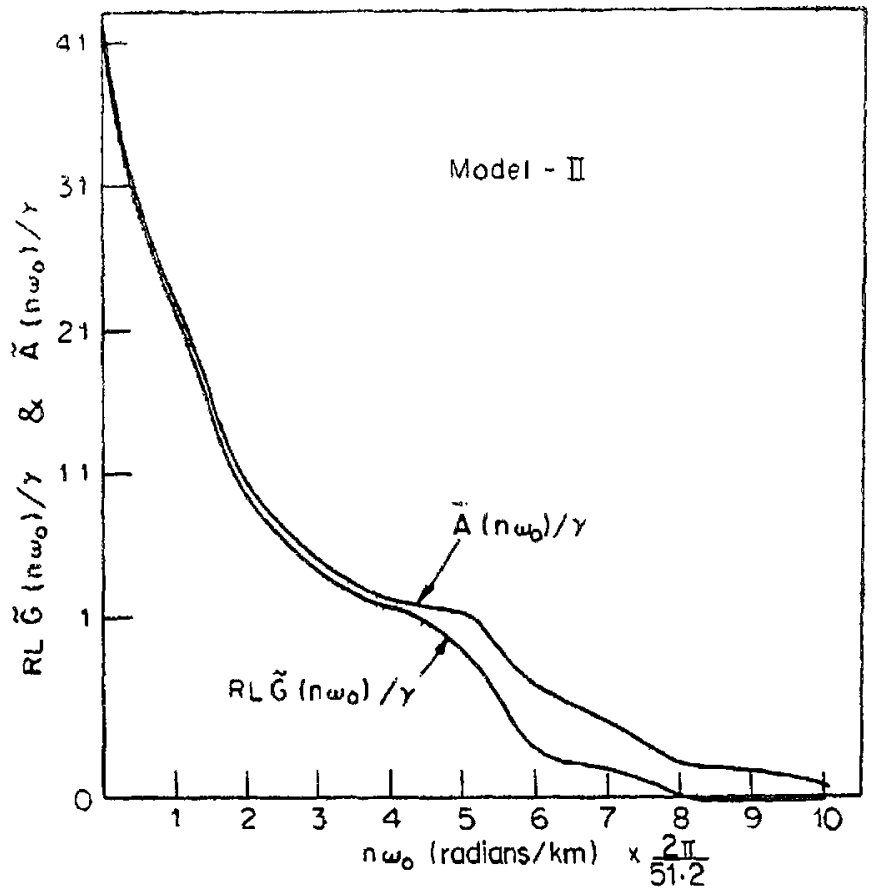

Figure 6. Graphs of $\bar{G}\left(n \omega_{0}\right) / \gamma$ and $\widetilde{A}\left(n \omega_{0}\right) / \gamma$ ys. $n \omega_{0}$ of the gravity effect.

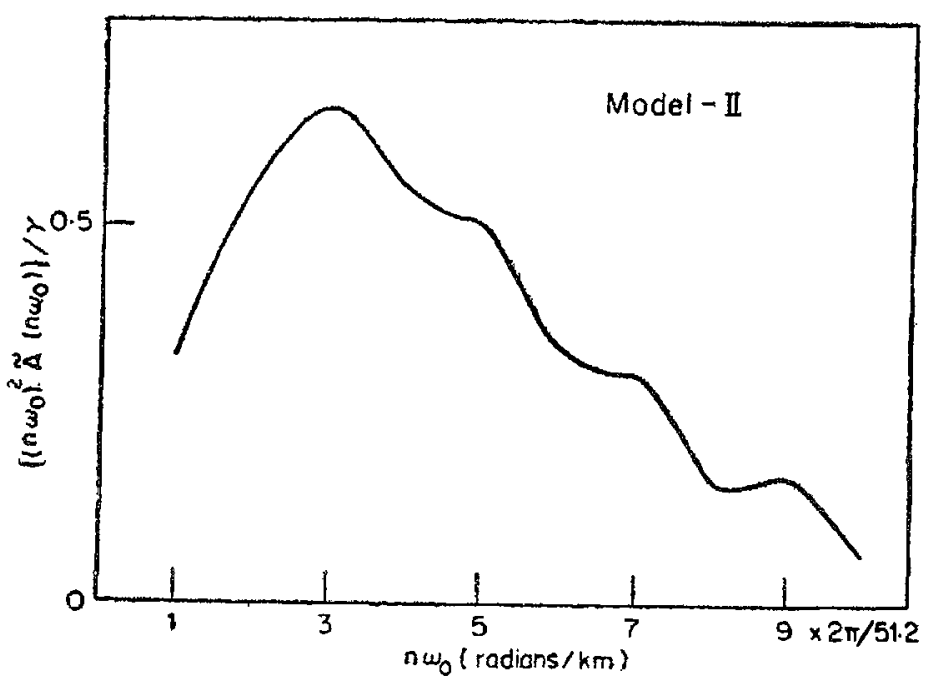

Figure 7. Graph of modified amplitude spectrum $\left(n \omega_{0}\right)^{2} \tilde{A}\left(n \omega_{0}\right) / v$ vs. $n$ as 


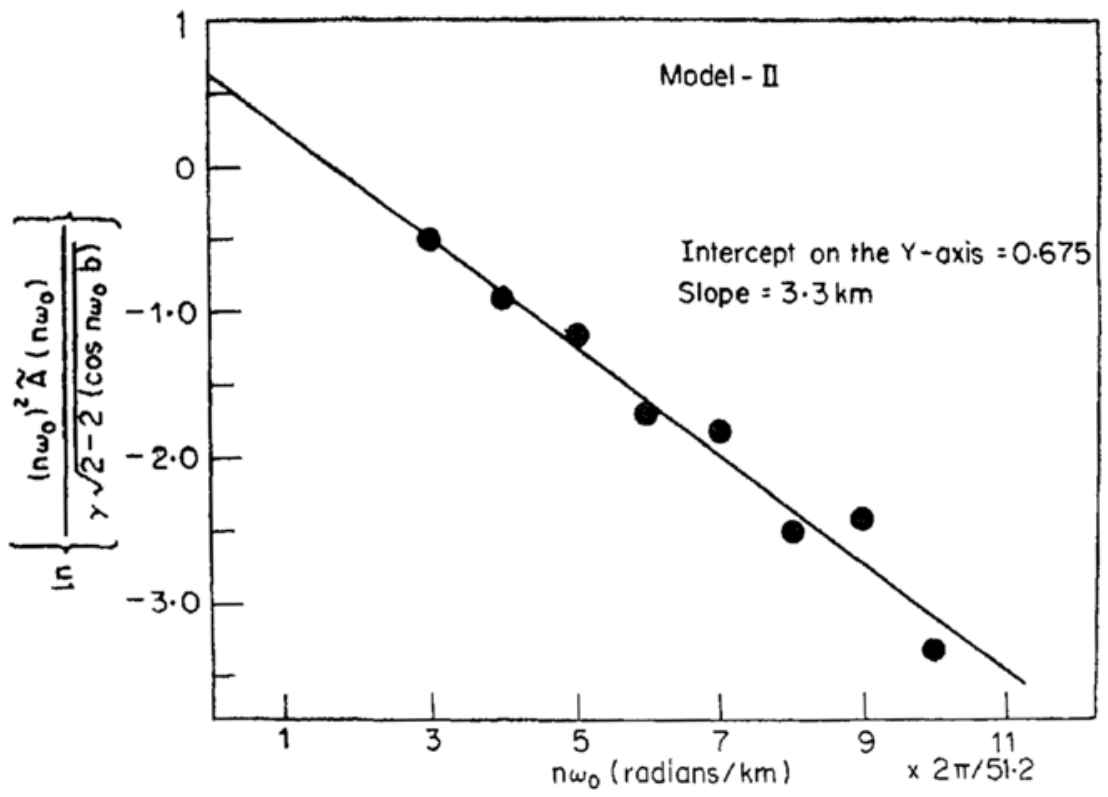

Figure 8. Graph of $\ln \left[\frac{\left(n \omega_{0}\right)^{n} \tilde{A}\left(n \omega_{0}\right)}{\gamma\left(2-2 \cos n \omega_{0} b\right)_{\frac{2}{2}}^{2}}\right]$ vs, $n \omega_{0}$

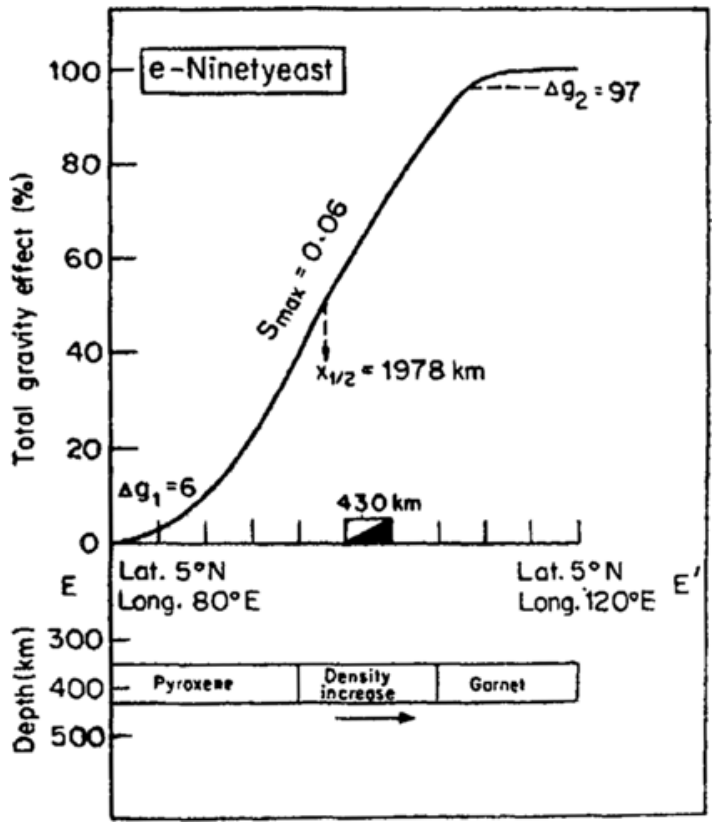

Figure 9. The gravity profiles and inferred gradational density ridges: Ninety east. 


\subsection{Field example}

The isogal map prepared by Bott (1971) using the potential coefficients upto harmonics of degree and order eight, is considered to be a reliable basis for the application of the variable-density model over most of the oceanic ridges (figure 2 of Garde 1974). In this section the plot of the percentage gravity effect versus distance along the profile $\mathrm{EE}^{\prime}$, ninety east (Latitude $5^{\circ} \mathrm{N}$ and $5^{\circ} \mathrm{N}$, and longitude $80^{\circ} \mathrm{E} .120^{\circ} \mathrm{E}$ ), is considered to test the applicability of the above method to evaluate the parameters of the causative body.

The profile $\mathrm{EE}^{\prime}$ (figure 9) is digitized at an interval of $430 / 12 \mathrm{~km}$ and the total number of digitized values are 128 (after taking first derivative). The first derivative of the percentage gravity effect is computed and the smoothened anomaly is shown in figure 10. The Fourier transform of the first derivative of the digitized percentage

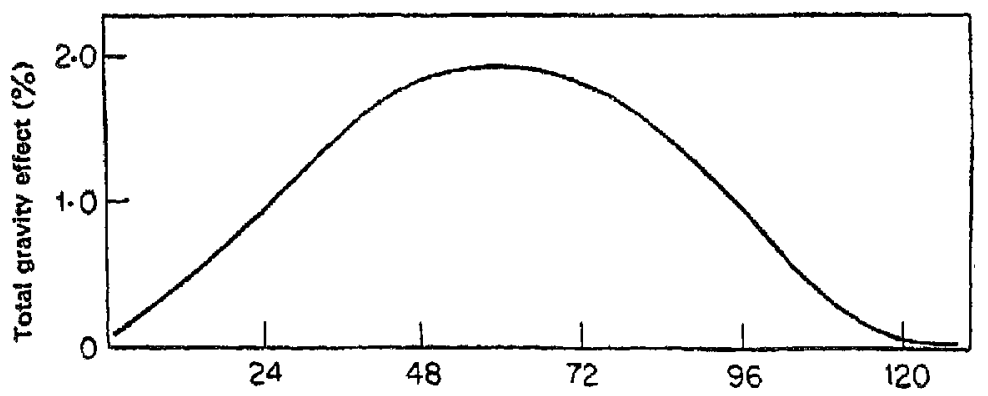

Figure 10. First derivative of the percentage gravity effect.

gravity effect is computed using FFT algorithm and the real component of the Fourie transform. Re $\tilde{G}\left(n \omega_{0}\right)$ and the amplitude spectrum $\tilde{A}\left(n \omega_{0}\right)$ vs. $n \omega_{0}$ are shown $\mathrm{i}$ Ggure 11. Here $N=128$ and $\omega_{0}=\frac{2 \pi}{\left(\frac{430}{12} \times 128\right)}$ (tadians $\left./ \mathrm{km}\right)$. Modified amplitud spectrum $\tilde{A}\left(n \omega_{0}\right)$ vs. $n \omega_{0}$ and $\ln \left[\frac{\left(n \omega_{0}\right)^{2} \tilde{A}\left(n \omega_{0}\right)}{\left(2-2 \cos n \omega_{0} b\right)^{1 / 2}}\right]$ vs. $n \omega_{0}$ are shown in figure 12 and figure $12 b$ respectively. Using (14), (16) and (17), the parameters of the causatix body viz. the width of the zone of density gradient $K$ and the depth to the bottom a1 evaluated from the figures 11 and $12 \mathrm{~b}$ and tabulated below (table 2).

Table 2. Field example.

\begin{tabular}{lcccc}
\hline Parameters & $\begin{array}{c}b \\
(\mathrm{~km} .)\end{array}$ & $\begin{array}{c}H_{1} \\
(\mathrm{~km} .)\end{array}$ & $\begin{array}{c}H_{\mathrm{a}} \\
(\mathrm{km} .)\end{array}$ & $\begin{array}{c}K \\
(\mathrm{gm} / \mathrm{c.c})\end{array}$ \\
\hline The Present technique & 1310 & 352 & 479 & 0.28 \\
Garde (1974) & 1290 & 350 & 430 & 0.30 \\
\hline
\end{tabular}




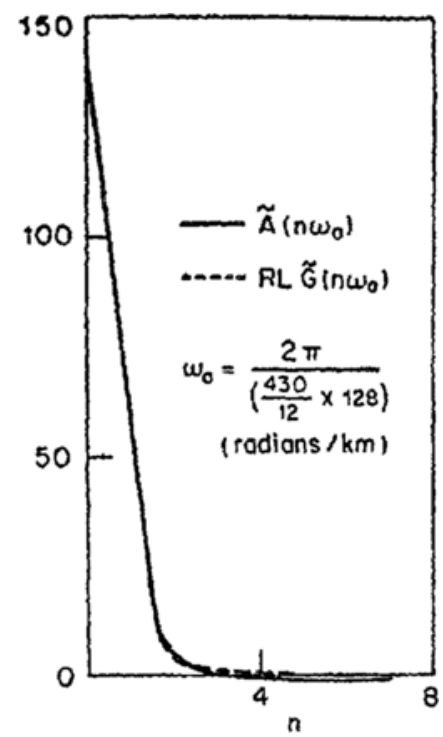

F lgure 11. Graphs of $\widetilde{G}\left(n \omega_{0}\right)$ and $\left.\widetilde{A(n} \omega_{0}\right)$ ys, $n \omega_{0}$.

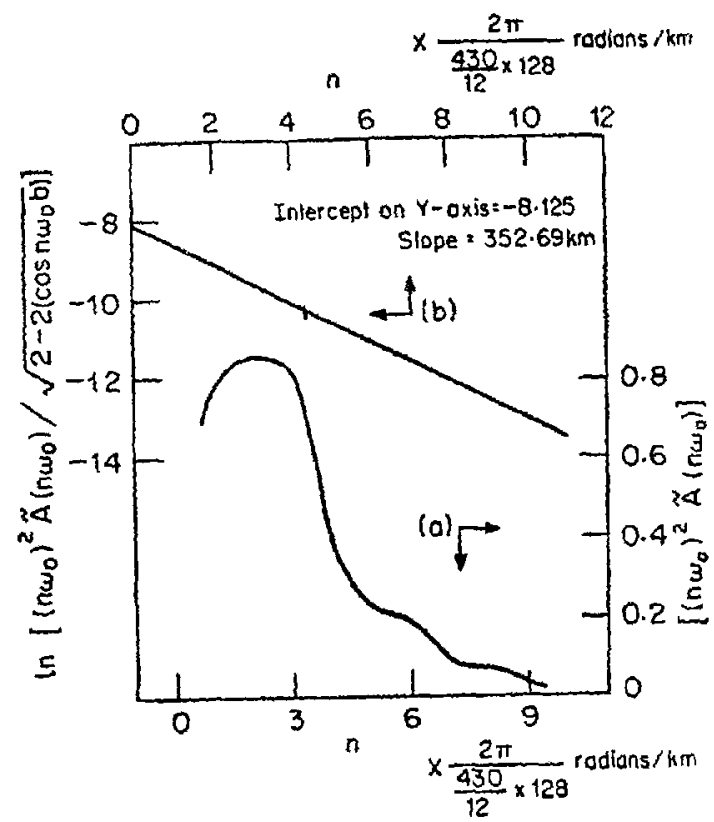

Figure 12. a. Graph of modified amplitude spectrum $\left.\left(n \omega_{0}\right)^{2} \widehat{A(n} \omega_{0}\right)$ vs. $n$ w.in b. Graph of $\ln \left[\frac{\left(n \omega_{0}\right)^{2} \tilde{A}\left(n \omega_{0}\right)}{\sqrt{2-2 \cos n \omega_{0}^{-}}}\right]$vs. $n \omega_{\mathrm{p}}$. 
The above parametric values, evaluated by the present technique, fairly agree with the values of Garde (1974). This shows that this method is relatively much simpler, as it has sound mathematics, than the Gendzwill (1970) technique which is based on type curves method.

\section{Acknowledgement}

The authors wish to thank the University Grants Commission, New Delhi, for providing financial support for "Software Project".

\section{References}

Bhimasankaram V L S, Mohan N L and Seshagiri Rao V 1977 Geophys. Prospect. 25 334-341

Bhimasankaram V L S, Mohan N L and Seshagiri Rao V 1978 Geoexploration, 16 259-266

Bott M H P 1971 Earth Planet Sci, Cilt, 1128

Cochran W T, Cooley O W, Favin D L, Helms H D, Kaenel R A, Lang, W W, Maling G C, Nelson

$D$ F, Rader C M and A Welch P D 1967. IEEE Trons. Audio Electraacoust. AU-15 45-55

Garde S C 1974 Phys. Earth Planet. Inter. 8 46-52

Gendzwill D J 1970 Geophysics 35 270-278

Mohan N L, Seshagiri Rao S V and Bhimasankaram, V L S 1980 Bull. Aust. Soc. Explor. Geophys.

V. 11, No. 3, pp. 134-138

Novosolitskii V M 1965 Izv. Phys. Solid Earth, Trans. Am. Geophys. Union No. 5, 300.

Rao K G C and Avasthi D N 1973 Geophys. Rrospect. 21 526-542 